\title{
The use of complementary and alternative medicine by people with cardiovascular disease: a systematic review
}

\author{
Suzanne J Grant ${ }^{1}$, Yu Sun Bin², Hosen Kiat ${ }^{2,3}$ and Dennis Hsu-Tung Chang ${ }^{1 *}$
}

\begin{abstract}
Background: Complementary and alternative medicine (CAM) may offer benefits as well as risks to people with cardiovascular disease. Understanding the prevalence and the nature of CAM use will encourage beneficial CAM therapies, prevent potential herb-drug interactions and foster communication between patients and physicians.

Methods: A systematic search of eight bibliographic databases was conducted for studies that investigated CAM use in patients with cardiovascular diseases. Two independent reviewers selected relevant abstracts and evaluated the quality of included studies.

Results: Twenty-seven studies were included. Prevalence of CAM use in cardiac patients ranged from 4\% - 61\%. Biologically-based therapies usage ranged from $22 \%$ to $68 \%$. Herbal medicines were used by between $2 \%$ and $46 \%$. A large proportion of patients did not inform medical practitioners about their CAM use and up to $90 \%$ of treating physicians did not discuss CAM use with their patients.

Conclusions: CAM use in patients with cardiovascular disease appears common. The findings suggest that the effects of CAM on medical management of cardiovascular disease may be overlooked and that patient-physician communication need to be strengthened.
\end{abstract}

\section{Background}

Cardiovascular disease (CVD) is the leading cause of morbidity and mortality in Australia. CVD affects four million Australians and accounted for 38\% of all deaths in 2004 [1]. Around $62 \%$ of people with CVD take medication for their condition, and given the chronic nature of CVD, this is an important part of long-term management. Effective medical management of CVD may be compromised by inappropriate use of complementary and alternative medicine (CAM). CAM use is estimated at between 9\% and $65 \%$ globally [2]. In Australia, one in two people regularly use CAM, and consumers spend more money on CAM than prescription drugs [3].

The Australian Therapeutic Goods Administration (TGA) defines complementary medicine as medicines containing herbs, vitamins, minerals, nutritional supplements,

\footnotetext{
* Correspondence: d.chang@uws.edu.au

${ }^{1}$ Centre for Complementary Medicine Research, University of Western

Sydney, Locked Bag 1797, Penrith South DC, NSW 2751, Australia

Full list of author information is available at the end of the article
}

homoeopathic medicines and certain aromatherapy products [4]. The TGA's definition does not cover some important non-ingestible CAM modalities such as osteopathy, massage, reiki, qigong, yoga and meditation. These modalities are included in a more comprehensive definition from the US National Centre for Complementary Medicine and Alternative Medicine (NCCAM) [5].

In cardiac patients, the use of CAM offers both risks and benefits. For instance, physical therapies such as qigong appear helpful for hypertension while coenzyme Q10 supplements have favourable effects in those with heart failure [6,7]. Biological therapies such as dietary supplements and herbal medicine may interfere with the action of prescription medications, a potentially harmful consequence. Herb-drug interactions are of concern in cardiac patients because of the narrow therapeutic window and range of cardiac medications. People with chronic diseases frequently use CAM therapies to manage their condition, and thus increase exposure to herb-drug interactions [8]. It is therefore important to understand the prevalence and the nature of CAM use 
Table 1 Databases, MeSH keywords, and qualifiers used in the search strategy

\begin{tabular}{l} 
Database \\
From inception - 20 April 2010 \\
\hline AMED \\
\hline Blackwell Synergy \\
\hline CINAHL \\
\hline Health \& Society \\
\hline PubMED Entrez (indexes \\
Medline and Biomed Central) \\
\hline Scopus (indexes EMBASE) \\
\hline Science Direct \\
\hline Web of Science
\end{tabular}

\section{Search terms}

MeSH: 'cardiovascular diseases' [exploded] AND ('complementary therapies' [exploded] OR 'dietary supplements[exploded] OR 'plants, medicinal' [exploded] AND 'data collection' [exploded] Where MeSH terms were unavailable, the following terms were combined: [complementary medicine\$ or complementary therapy\$ or alternative medicine\$" or "supplement\$ or herb\$ or homeopath\$ or osteopath\$ or acupuncture or Chinese medicine\$ or mind-body therapy\$] AND cardiovascular disease AND ['utilisation" OR "utilization" OR ' prevalence' OR 'use']

in this patient cohort to encourage beneficial CAM therapies and to prevent potential herb-drug interactions. In the current study, we conducted a systematic review of the literature to determine the prevalence of CAM use by cardiac patients.

\section{Methods}

\section{Literature search strategy}

We searched eight databases for articles published in peer-reviewed journals that reported primary data on the prevalence of CAM use among people with cardiovascular

Table 2 Quality Assessment of Studies

\begin{tabular}{|c|c|c|c|c|}
\hline QAT Item & Brief Definition & $\begin{array}{l}\text { Points } \\
\text { Awarded }\end{array}$ & $\begin{array}{l}\text { Frequency } \\
\text { of studies } \\
\%(n)\end{array}$ & Reference \\
\hline \multicolumn{5}{|l|}{ STUDY METHODS } \\
\hline Low risk & $\begin{array}{l}\text { Prospective/current } \\
\text { data collection }\end{array}$ & 2 & $11(3)$ & {$[9-11]$} \\
\hline Some risk & $\begin{array}{l}\text { Retrospective data } \\
\text { collection }<12 \text { months }\end{array}$ & 1 & $78(21)$ & {$[12-32]$} \\
\hline $\begin{array}{l}\text { Piloted questionnaire } \\
\text { (or interview schedule) }\end{array}$ & $\begin{array}{l}\text { Any pilot or previous use } \\
\text { of study material }\end{array}$ & 1 & $26(7)$ & {$[13,22,23,25,28,29,31]$} \\
\hline $\begin{array}{l}\text { Address potential } \\
\text { sources of bias }\end{array}$ & $\begin{array}{l}\text { Report efforts to address nonresponsive } \\
\text { bias or information bias }\end{array}$ & 1 & $7(2)$ & {$[11,29]$} \\
\hline $\begin{array}{l}\text { Adjust for } \\
\text { potential confounders }\end{array}$ & $\begin{array}{l}\text { Any adjustment of confounders in analyses } \\
\text { of variables associated with CAM use }\end{array}$ & 1 & $44(12)$ & {$[9,11,12,14,15,22-24,26,32-34]$} \\
\hline \multicolumn{5}{|l|}{ SAMPLING } \\
\hline Response rate & $\begin{array}{l}\text { Where response rate }=\text { (no. of participants in } \\
\text { the study/No of people invited to take part) } \times 100\end{array}$ & 1 & $48(13)$ & {$[9,11,12,14,15,17-19,21,26,29,32,34]$} \\
\hline $\begin{array}{l}\text { Representative } \\
\text { sampling strategy }\end{array}$ & $\begin{array}{l}\text { Any attempt to a representative sample } \\
\text { of the larger population }\end{array}$ & 1 & $26(7)$ & {$[9,11,12,23-25,30]$} \\
\hline \multicolumn{5}{|l|}{ PARTICIPANT'S CHARACTERISTICS } \\
\hline Specific diagnosis & Report participants' diagnoses & 1 & $100(27)$ & All studies \\
\hline Indicator of socioeconomic status & Report participants' socioeconomic status & 0.5 & $67(18)$ & {$[9,12-16,18,19,22-24,28,30-33,35]$} \\
\hline Age & Report participants' ages & 0.5 & $100(27)$ & All studies \\
\hline Ethnicity & Report participants' ethnicity & 0.5 & $56(15)$ & {$[10,12,14,16,19,22-24,26,30-35]$} \\
\hline Gender & Report participants' gender & 0.5 & $100(27)$ & All studies \\
\hline \multicolumn{5}{|l|}{ CAM USAGE } \\
\hline CAM definition & $\begin{array}{l}\text { Information about the definition of CAM/a } \\
\text { list of CAM modalities provided to participants }\end{array}$ & 2 & $74(20)$ & {$[9,11-20,22-25,27,29-33,35]$} \\
\hline $\begin{array}{l}\text { Use of CAM } \\
\text { modalities assessed }\end{array}$ & $\begin{array}{l}\text { Report the prevalence of use of } \\
\text { specific CAM modalities }\end{array}$ & 1 & $100(27)$ & All studies \\
\hline $\begin{array}{l}\text { Frequency/duration } \\
\text { of CAM uses }\end{array}$ & $\begin{array}{l}\text { Report how often or for what duration the } \\
\text { CAM were/are used by study participants }\end{array}$ & 1 & $19(5)$ & {$[24,25,28,30,32]$} \\
\hline Reasons for CAM use & $\begin{array}{l}\text { Report the reasons for the use of } \\
\text { CAM by study participants }\end{array}$ & 2 & $56(15)$ & {$[9,12,15-18,22,23,26,28,30,3$} \\
\hline
\end{tabular}


disease. Details of the search strategy are provided in Table 1. The period of the search was from the inception of each database until 20 April 2010.

Studies were included if they reported the prevalence of CAM use in patients either attending for cardiac care or reporting a cardiovascular condition. If abstracts were unavailable or unclear, the full-text article was retrieved. Studies were excluded where the (i) study methods were not described, (ii) data on participants with cardiovascular disease could not be separated from other study populations, or (iii) the study was not in English. Reference lists were manually searched to locate articles not found by the above methods. Two independent reviewers (Grant and Chang) examined titles and abstracts of the articles for inclusion or exclusion. Disagreements were resolved by reviewing the full papers and discussion. Data was extracted according to a predefined format covering the study methodology (Table 2), participant demographics, and CAM use (Table 3).

\section{Quality assessment}

There is a paucity of methods for assessing the quality of observational studies [36,37]. Bishop et al. (2010) recently developed a Quality Assessment Tool (QAT) for a systematic review of the prevalence of complementary medicine use in paediatric cancer based on the principles of the STROBE statement [38]. We used a modified version of the QAT in the present review (Table 2). Like Bishop et al. (2010), we weighted these items according to their respective significance through consensus of the authors [38] and the two independent reviewers assessed each study using the QAT, with disagreements resolved by discussion.

\section{Statistical analyses}

There are two methods commonly used to summarise prevalence rates across observational studies: variations in frequency estimates can be displayed graphically or summarized with quantiles around measures of central tendency [39].We chose to display the results graphically with no meta-analysis due to the variation in definitions of $\mathrm{CAM}$ and the heterogeneous methodologies of the included studies.

\section{Results}

Our database search found 2,124 articles, of which 112 full-text articles were retrieved. Three studies were identified that utilised the same dataset of the 2002 USA National Health Interview Survey $[12,40,41]$. We included only Yeh et al. [12] which covered the cohorts of the other two studies. In total the search identified 27 studies suitable for inclusion in our review (Table 3). All were crosssectional studies.

\section{Study characteristics \\ Scope}

The bulk of the studies looked at CAM use in general. Three of these utilised the National Institute of Health's defined categories of CAM [12-14], while eight studies provided comprehensive yet differing definitions of CAM [9,15-20,33]. Two studies did not define CAM but used open-ended questions to elicit the CAM therapies utilised [21,34]. Thirteen studies looked specifically at biological-based therapies, such as vitamins, minerals and dietary supplements [10,22-26], herbal medicine only $[27,28]$ or a combination of both $[29-31,35]$ and one study reported on the use of chelation therapy following angioplasty [11]. The remaining study looked specifically at mind-body therapy [32].

Most studies reported on CAM prevalence in a cohort of people with cardiovascular disease although some reported on a specific diagnosis. Two studies reported on CAM use in people with stroke $[17,23]$, five on chronic heart failure $[21,26,29,30,35]$ and four examined CAM prevalence in people with hypertension only $[13,14,20,24]$.

\section{Location/setting}

Twelve of the 27 studies were undertaken in the United States $[10,12,15,16,18,19,22,23,26,30,31,33]$ and six in Canada $[9,11,17,25,29,32]$. The remaining nine were conducted in the UK [14,34], Hong Kong [27], India [20], Italy [35], Korea [24], Nigeria [13], Spain [21], and Turkey [28].

Participants were typically recruited in outpatient clinics or hospital settings. Six of the 27 studies used national survey data $[9,11,12,22-24]$.

\section{Sample size}

Sample sizes ranged from 65 [21] to 10572 [12]. The two largest studies were the US National Health Interview Survey [12], and a survey of chelation in 5,854 coronary angiography patients in Canada [11].

\section{Data collection}

In these studies, research methods used for data collection included standardised, self administered surveys $[11,14,18,19,21,26,29,32,34]$ and face-to-face interviews using a structured $[12,24,25,31]$ or semi-structured instrument $[10,13,16,20,27,28,35]$. The remaining studies used mixed methods, either a combination of face-to-face and phone interview [15,30], face-to-face interview and a medical examination [23], data collection from medical records, [22,33] or a phone interview and information from medical records [9]. One study used phone interview alone [17]. 
Table 3 Characteristics of studies

\begin{tabular}{|c|c|c|c|c|c|}
\hline Author (Year) & Mode of data collection & $\begin{array}{c}\text { Sample } \\
\text { size }\end{array}$ & Diagnosis & CAM Modalities Investigated & Prevalence* $(\%)$ \\
\hline Ackman et al. (1999) & Standardised, self-administered survey & 180 & CHF & $\begin{array}{l}\text { Vitamins/minerals, nutritional supplements, health } \\
\text { food or herbal products; OTC medication }\end{array}$ & $59 \wedge$ \\
\hline Ai et al. (2004) & $\begin{array}{l}\text { Combination face-to-face interviews } \\
\text { and telephone survey }\end{array}$ & 225 & $\begin{array}{l}\text { Cardiac } \\
\text { surgery }\end{array}$ & $\begin{array}{l}\text { Relaxation, spiritual healing, herbal medicine, } \\
\text { megavitamins, acupuncture, chiropractic, massage, } \\
\text { biofeedback, hypnosis, imagery, homeopathy; includes exercise. }\end{array}$ & 80.9 \\
\hline Albert et al. (2009) & Structured telephone or face-to-face interview & 374 & Heart failure & Vitamins, minerals, herbal products, OTC medication & $11.5 \wedge \wedge$ \\
\hline $\begin{array}{l}\text { Amira \& Okubadejo } \\
\text { (2007) }\end{array}$ & Semi-structured interview (face-to-face) & 225 & Hypertension & $\begin{array}{l}\text { NIH Categories: whole medical systems, mind-body therapies; } \\
\text { dietary supplements \& herbs; energy therapy and manipulation } \\
\text { \& touch therapy; plus sub-categories. }\end{array}$ & 39.1 \\
\hline Artz et al. (2006) & $\begin{array}{l}\text { Combination of standardised survey } \\
\text { (face-to-face) and medical records }\end{array}$ & 315 & CVD & $\begin{array}{l}\text { Non-vitamin/mineral dietary supplement, vitamin/mineral } \\
\text { dietary supplement. }\end{array}$ & 4 \\
\hline Barraco et al. (2005) & Semi-structured face-to-face interview & 223 & CAD & $\begin{array}{l}\text { Folk remedies, herbal therapy, homeopathy, megavitamin } \\
\text { therapy (not daily vitamin), minerals (not calcium or iron), } \\
\text { native American medicine, Tibetan medicine, traditional Chinese } \\
\text { medicine (includes exercise and prayer as CAM) }\end{array}$ & 63 \\
\hline $\begin{array}{l}\text { Blackmer } \\
\text { and Jefromova (2002) }\end{array}$ & Standardised telephone survey & 136 & $\begin{array}{l}\text { Stroke or } \\
\text { subarachnoid } \\
\text { haemorrhage }\end{array}$ & $\begin{array}{l}\text { Acupuncture, massage, chiropractic, reflexology, magnetic } \\
\text { therapy, hyperbaric oxygen, herbal supplements, vitamins, } \\
\text { spiritual healing, reiki, chelation, relaxation }\end{array}$ & 26.5 \\
\hline Buettner et al. (2007) & $\begin{array}{l}\text { Combination of standardised survey } \\
\text { (face-to-face) and medical examination; } \\
\text { part of the annual National Health and } \\
\text { Nutrition Examination Survey (NHANES) }\end{array}$ & 1066 & CAD or Stroke & Vitamins, minerals, other dietary supplements & 61 \\
\hline Chagan et al. (2005) & Structured face-to-face interview & 198 & CVD & Biologically based therapies (herbal medicine, Vitamins \& minerals) & 42 \\
\hline Dal Corso et al. (2007) & Semi-structured face-to-face interview & 153 & $\mathrm{CHF}$ & Herbal remedies, integrators (vitamins, minerals, salts), OTC medications & $30 \wedge$ \\
\hline Decker et al. (2007) & $\begin{array}{l}\text { Combination of face-to-face interview, } \\
\text { and medical records. }\end{array}$ & 596 & CAD & $\begin{array}{l}\text { Biofeedback, acupuncture, relaxation therapy, home remedies, } \\
\text { and chelation therapy }\end{array}$ & 19 \\
\hline Gohar et al. (2008) & Standardised, self administered survey & 153 & Hypertension & $\begin{array}{l}\text { NIH Categories: whole medical systems, mind-body } \\
\text { therapies; dietary supplements \& herbs; energy therapy and manipulation } \\
\text { \& touch therapy; (includes prayer) }\end{array}$ & 37.9 \\
\hline Greenfield et al. (2008) & Standardised, self administered survey; & 422 & CVD & $\begin{array}{l}\text { Open ended question on CAM; vitamins \& minerals, } \\
\text { exercise, acupuncture, homeopathy, chiropractic, massage }\end{array}$ & 9.2 \\
\hline Krasuski et al. (2006) & Standardised, self administered survey & 210 & CVD & $\begin{array}{l}\text { Herbal medications, vitamin supplements (unless prescribed), } \\
\text { dietary supplements, visits to alternative medicine providers }\end{array}$ & 54 \\
\hline Lee and Kim (2009) & Structured face-to-face interviews & 1434 & Hypertension & Dietary supplements & 23.7 \\
\hline Leung et al. (2008) & Standardised, self administered survey (mail out) & 661 & CAD & $\begin{array}{l}\text { Mind-body therapy: meditation, yoga, qigong, tai chi, relaxation } \\
\text { techniques, deep breathing exercise, visualisation, guided imagery, quiet } \\
\text { sitting, mantra, muscle relaxation, and other (not including prayer) }\end{array}$ & 35.1 \\
\hline Liu et al. (2000) & Standardised, self administered survey & 263 & Cardiac surgery & $\begin{array}{l}\text { Ayurveda, Acupuncture, Biofeedback, Chelation, Chiropractic, } \\
\text { Energy healing, guided imagery, Herbs, Homeopathy, Hypnosis, Massage } \\
\text { therapy, Meditation/relaxation, Naturopathy, Nutritional therapy, Prayer/pastoral } \\
\text { counselling, qi gong, reflexology, tai chi, vitamins, yoga, other }\end{array}$ & 75 \\
\hline
\end{tabular}


Table 3 Characteristics of studies (Continued)

\begin{tabular}{|c|c|c|c|c|c|}
\hline $\begin{array}{l}\text { Martinez-Selles } \\
\text { et al. (2004) }\end{array}$ & Standardised, self administered survey & 65 & $\mathrm{CHF}$ & $\begin{array}{l}\text { CAM use was asked in the context of "use of over the counter } \\
\text { drugs and alternative medicine" }\end{array}$ & 12 \\
\hline Pharand et al. (2003) & Structured face-to-face interviews & 306 & CVD & $\begin{array}{l}\text { Vitamins or mineral products, nutritional supplements, health food or } \\
\text { herbal products (home remedies, oriental remedies) }\end{array}$ & $22.9 \wedge$ \\
\hline Quan et al. (2001) & Standardised, self administered survey & 5854 & CAD & Chelation therapy & 7.9 \\
\hline Shafiq et al. (2003) & Structured structured face-to-face interviews & 521 & Hypertension & $\begin{array}{l}\text { Ayurvedic medicine, herbal medicine, homeopathy, spiritual healing, } \\
\text { diet therapy and acupuncture }\end{array}$ & 63.9 \\
\hline Stys et al. (2004) & Physician interview & 187 & CVD & Vitamin, mineral or herbal supplements & 57 \\
\hline Wong et al. (2003) & Physician interview & 107 & CVD & Herbal medicine & 26 \\
\hline Wood et al. (2003) & $\begin{array}{l}\text { Combination of structured phone interview, } \\
\text { medical records as part of a larger study: Improving } \\
\text { Cardiovascular Health in Nova Scotia (ICONS) }\end{array}$ & 107 & CVD & $\begin{array}{l}\text { Megavitamins, Herbal therapy, Other nutritional supplements, } \\
\text { Chiropractic, Massage therapy, Acupuncture, Homeopathy, Folk remedies, } \\
\text { Exercise, Energy healing, Chelation,Biofeedback, Relaxation therapy, Spiritual } \\
\text { healing, Hypnosis, Self-help groups (includes exercise) }\end{array}$ & 64 \\
\hline *Yeh et al. (2006) & $\begin{array}{l}\text { Structured face-to-face interview; } 2002 \\
\text { National Health Interview Survey }\end{array}$ & 10572 & CVD & $\begin{array}{l}\text { NIH Categories: whole medical systems, mind-body therapies; dietary supplements } \\
\& \text { herbs; energy therapy and manipulation \& touch therapy; (excluding prayer) }\end{array}$ & 36 \\
\hline$\overline{\text { Yilmaz et al. (2007) }}$ & Semi-structured face-to-face interview & 310 & CVD & Herbal medicine & 26.5 \\
\hline Zick et al. (2005) & Standardised, self administered survey & 252 & $\mathrm{CHF}$ & Herbs, vitamins, minerals, amino acids, other & 32.5 \\
\hline
\end{tabular}

$\wedge$ No overall prevalence reported to the CAM, the figure presented here is for dictary supplement usage.

$\wedge \wedge$ No overall prevalence reported for CAM, the figures presented here refer to multivitamin use and herbal therapy use respectively. 


\section{Study quality}

The quality of the studies examined in the present review varied significantly ranging from meeting only $25 \%$ of the QAT criteria [21] to meeting more than 75\% of the QAT criteria [12]. Eight studies, representing 30\% of the total, scored less than $50 \%$ on the QAT (QAT $\leq 8 / 16$ ) [10,13,19,21,26,27,33-35]. Most studies clearly reported the CAM modalities that were being assessed and provided a reasonable definition although the lists of CAM modalities included in these definitions varied considerably. The included studies were fairly diligent in their collection of demographics (age, gender, ethnicity and socioeconomic data) although some studies conducted in regions or countries of more homogenous ethnicity did not report ethnicity of the study population. Data collection was commonly retrospective and the studies were generally poor in their reporting of the frequency and duration of CAM use, validation of the survey instrument, and providing a representative sample.

\section{Prevalence of CAM use among CVD patients}

The prevalence of CAM use among people with CVD ranged from $4 \%$ [22] to 61\% [23]. CAM modalities investigated were in some studies limited to types of biological-based therapies [10,21-24,26-29,31], a single therapy such as mind-body therapy [32] or chelation [11]. In the seven studies which used comprehensive lists or definitions of CAM [12-14,17,18,20,33], prevalence of CAM usage ranged from $19 \%$ to $64 \%$.

Six studies were excluded from Figure 1 as we could not separate the use of exercise $[9,15]$ and/or prayer $[13,16]$ from the overall CAM usage data. In the other three studies [25,30,35], OTC medications or nutritional supplements and health food could not be extracted from the overall CAM figure.

\section{Types of CAM modalities used}

Biological based therapies Of the 23 studies that reported on biologically-based therapies, only three provided an overall prevalence figure and breakdown into herbal medicine or dietary supplements [10,12,20]. Seven studies $[10,12,13,18,23,26,31]$ provided data on overall biologically-based therapies usage that ranged from $22 \%$ [12] to $68 \%$ [18]. Eight studies provided only separate figures for herbal and/or dietary supplements and did not ascertain an overall prevalence. Biologically-based therapies were reported as an average of two supplements per user $[28,31]$ while another study recorded an average of three supplements per user [10].

Herbal Medicine In sixteen studies reporting the prevalence of herbal medicine use by people with CVD, herbal medicines were used by between $2 \%$ [17] and $46 \%$ [20] of respondents (Figure 2). Data for Zick (2005) was not presented in Figure 2 as herbal medicine could not

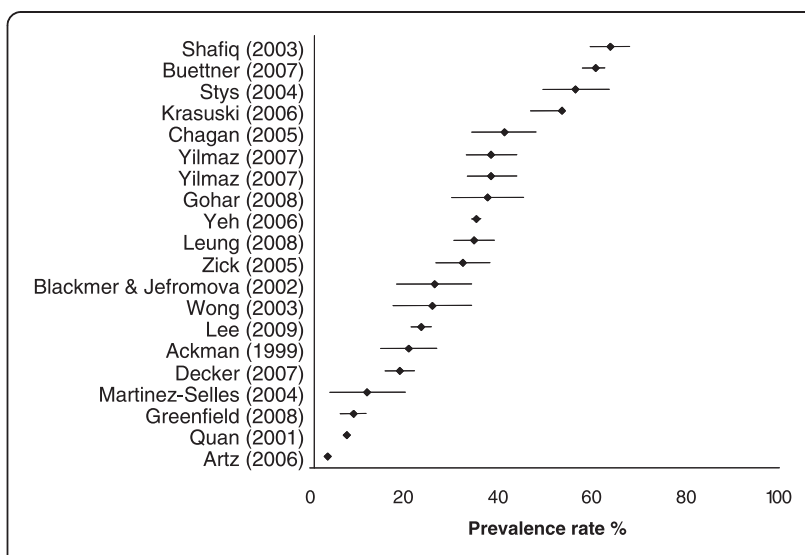

Figure 1 Prevalence ( $\% \pm 95 \%$ confidence interval) of CAM usage by people with CVDs.

be separated from vitamins and minerals. The top five individual herbs utilised were echinacea (2\% [26] to $14 \%$ [30]), garlic (1\% [28] to 69\% [13]), ginger (1\% [29] to $24 \%$ [13]), ginkgo (1\% [26] to $9 \%$ [30]), and ginseng (1\% [25] to $6 \%$ [29]).

Vitamin, Minerals and Other Dietary Supplements The thirteen studies that provided prevalence data on vitamins, minerals and other dietary supplements showed

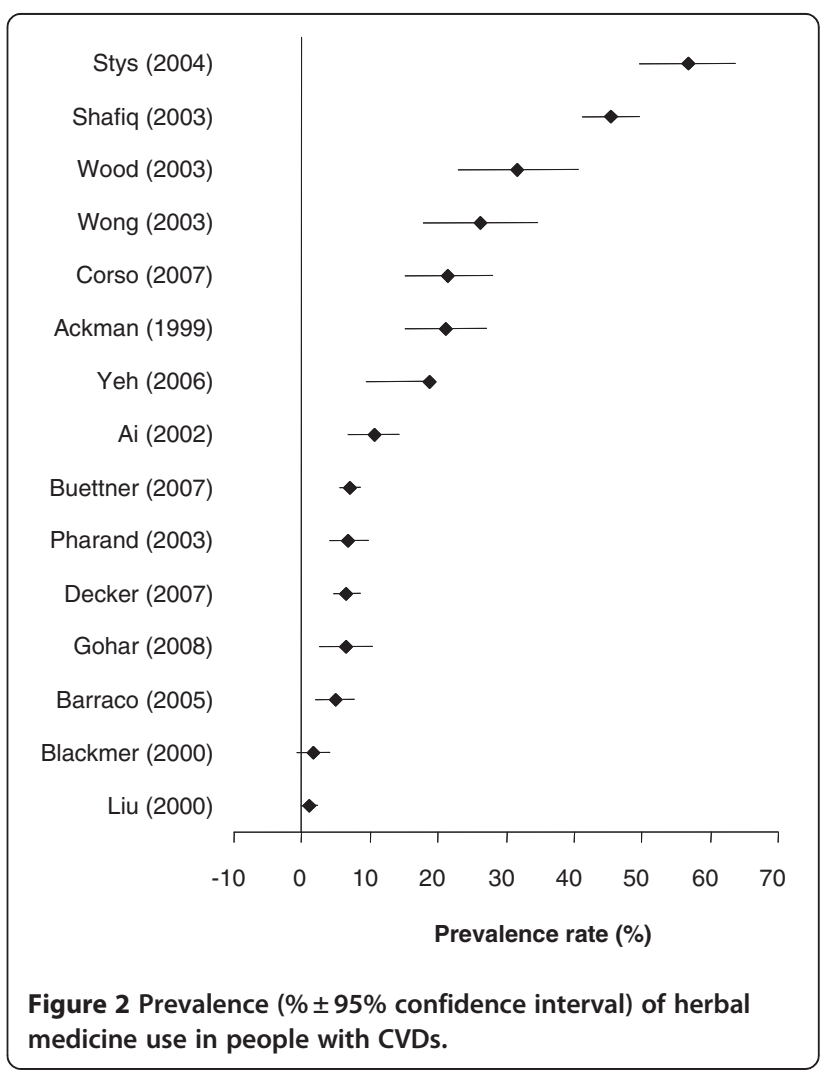




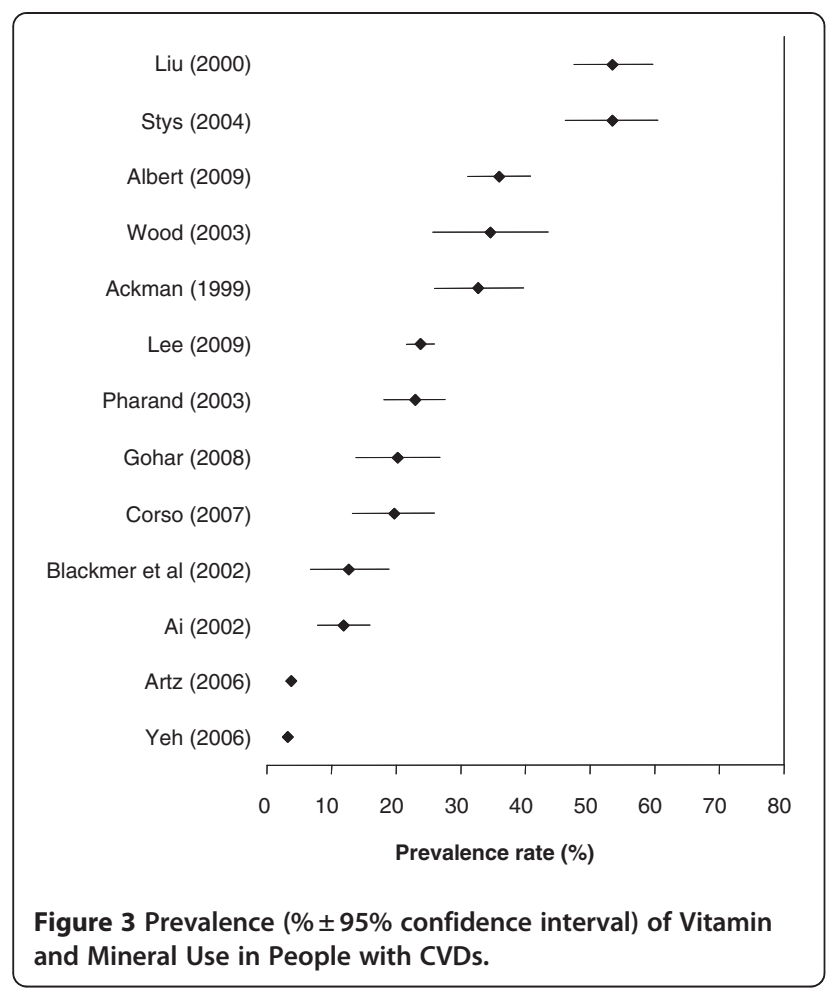

usage to be between $3 \%$ and $54 \%$ (Figure 3). The most common supplements were vitamin B/B12 or B complex, vitamin $\mathrm{C}$, vitamin $\mathrm{E}$, calcium, glucosamine/chondroitin, coenzyme Q10, calcium and magnesium.

Mind-body therapies Seven studies [12,14,15,17,19,32,33] reported on the prevalence of mind-body therapy (MBT) usage, which ranged from 2 to $57 \%$. An additional study [13], reported on the prevalence of mind-body connection (3.4\%) but this was limited to prayer and fasting. Deep breathing and meditation were the most common MBT therapies among the CVD participants. The main reasons for MBT usage were for psychological and emotional wellbeing.

\section{Physician awareness of patients' CAM use}

Physician awareness of their patient's CAM therapy use was reported in six studies [12,16-18,28,31]. Awareness was lowest in the Turkish study, 8\% [28], and was between $39-65 \%$ in the others $[12,16,18,31]$. The reason for nondisclosure to physicians about CAM use was investigated in two studies. Reasons given were fear that their physician might disapprove [17] and that their physician had not enquired about their CAM use [16].

\section{Reasons for CAM use}

Twelve studies investigated CAM users' perceptions of CAM or reasons for CAM use [9,12,15$18,20,26,30,31,34,35]$. CAM was thought to be of greater benefit than conventional medications by $15 \%$ of users in two studies $[9,18]$. One study reported that $59 \%$ of patients chose CAM due to adverse drug reactions to conventional therapy [20]. Overall well-being and promoting good health were the main reasons given for taking vitamins and herbal therapy in one study [30]. Two studies reported that CAM was a perceived remedy by $40 \%$ [15] and 57\% [9] of users, and $28 \%$ reported that it had a proven benefit for their condition [9].

The use of CAM specifically to treat cardiovascular disease was reported in six studies $[9,16,18,26,28,31]$. In patients with heart failure, up to $82 \%$ of CAM users were taking a supplement specifically for cardiovascular health [26]. Wood et al. (2003) and Chagan et al. (2005) reported that 43\% [9] and 65\% [31] of CAM users used CAM for their CVD, and in the remaining four studies, between $7 \%$ [18] and 23\% [16,28] had used CAM for their CVDs.

Five studies reported that users of CAM felt that biologically-based therapies were safe or had fewer side effects than conventional medications $[9,15,18,31,35]$. This perception ranged from $29 \%$ to $45 \%$ of CAM users in four of the five studies, and in the remaining study $3 \%$ of patients reported that the reason for using CAM therapies was due to fewer side effects compared to conventional treatment [9].

\section{Concurrent use of biological-based therapies and prescription medication}

Seven studies reported data on the concomitant use of prescription medication and biological- based therapies $[9,15,18,22,23,27,31]$. Aggregation of data was difficult due to variations in method although useful insights are provided by these investigations. On average, cardiovascular patients consumed seven prescribed medications and two herbal, vitamin or mineral products daily [9]. One study undertook an examination of medical records and identified 42 potential herb-drug interactions [31]. Two studies found that people with cardiovascular disease had taken dietary supplements or herbal medicine with warfarin [9,27]. In the Canadian study, $13 \%$ of patients had used a dietary supplement in conjunction with warfarin, amiodarone, sotalol, or digoxin [9]. In the Hong Kong study, 26\% of patients on warfarin had taken a herbal medicine in the week prior to interview [27]. Taking medication such as aspirin, beta-blockers, ACE inhibitors, statins and warfarin did not appear to alter the likelihood of using biologicalbased therapies [18].

Compliance to prescribed medication was examined in three studies $[14,35,42]$. The use of biological-based therapies was found to not effect compliance to antihypertensive medication, except in one study where females had lower compliance [14]. In a study of outpatients with heart failure taking herbal medicine reported that 1 in 22 
patients reduced or interrupted heart failure medications [35].

\section{Discussion}

The results indicate that CAM use is common in cardiac patients but the prevalence of CAM use varies significantly (4\%-61\%). The large range found is consistent with other reviews in the CAM literature $[2,43]$. The findings have strong implications for both clinical practice and research in this field. The lack of specific and consistent definitions of CAM in the reviewed studies contribute to the variability observed and has made generalisations difficult. A standard and complete definition of CAM use would facilitate meta-analysis in future studies [43].

The reasons for CAM use vary remarkably between different cohorts although six studies did find that patients used CAM specifically for the management of their CVDs. Although our review has found inconsistent results with regard to the association between CAM use and compliance, some evidence exists to suggest that CAM use may affect the compliance of prescription medicines [14,35]. A patients' belief that their CAM usage help manage their CVD may give them a false sense of security that may lead to a reduction of their concurrently medicines.

We found across the studies that patients with CVD are likely to be using more than one CAM product simultaneously $[9,10,23,28,31]$. There appeared to be little awareness that there may be interactions with their prescription medication, having potential additive or negative effects on the therapeutic levels of their medication or a harmful adverse effect $[28,31,35]$. Supplemental potassium was taken by $20 \%$ of patients in one study [29], which can result in adverse outcomes when used together with commonly prescribed medications such as angiotensin converting enzyme inhibitors, aldosterone receptor antagonists, or angiotensin receptor blockers. The potential effects and implications of herb-drug interaction with CVD medications have been discussed in detail elsewhere $[44,45]$.

It is of great concern that a large proportion of medical practitioners (35 - 92\%) were unaware of the CAM use by their patients $[12,16-18,28,31]$. Although patients may be reluctant to disclose CAM use because they fear disapproval, doctors also do not appear to be asking their patients about CAM use [31].

The results of our review are restricted in several aspects. For example, the quality of the reviewed studies was highly variable. Data collection in most of the studies was retrospective. This led to high variability in the resulting prevalence rates and may have introduced significant recall bias. Many studies also lacked the use of a validated survey, a representative sample, and rarely did the study authors address potential biases arising from their methods. Many of the studies failed to report the frequency and duration of CAM use. Several studies made use of clinical samples, but few provided objective data on the health status of the patients. The results presented here should therefore be treated with caution. We were only able to include studies published in the English language and therefore the findings have limited generalisability outside of English-speaking regions. However we note that it is within countries such as Australia and the United States where use and concerns about CAM are growing the fastest. Therefore the current study provides much needed information on these areas.

\section{Conclusions}

The use of CAM is common in patients with cardiovascular conditions. A high proportion of patients using CAM believe CAM has remedial benefits, and were at least as safe as or safer than their prescribed treatments. CVD patients were often unwilling to inform their medical practitioners of CAM use. Many commonly used CAM products have the potential to interfere with the intended action of prescription medications. In addition, the CAM use may have negative impacts on the compliance with prescription medications. Better education of patients, medical practitioners and pharmacists is needed to improve understanding of the risks and benefits of CAM use. Future studies are required to determine the impacts of CAM use in CVD patients, particularly its clinical and prognostic impact when used in conjunction with prescription medicines.

\section{Competing interests}

The authors declare that they have no competing interests.

\section{Authors' contributions}

SJG, YSB and DHC conducted the literature review and evaluated the articles recruited in the study. HK contributed to the design of the study. SJG drafted the manuscript and all other authors contributed to its preparation. All authors read and approved the final manuscript.

\section{Acknowledgements}

N/A

\section{Author details}

${ }^{1}$ Centre for Complementary Medicine Research, University of Western Sydney, Locked Bag 1797, Penrith South DC, NSW 2751, Australia. ${ }^{2}$ Cardiac Health Institute, 173 Shaftsbury Road, Eastwood, NSW 2122, Australia. ${ }^{3}$ The Australian School of Advanced Medicine, 2 Technology Place, Macquarie University, Sydney, NSW 2109, Australia.

Received: 31 August 2011 Accepted: 10 April 2012

Published: 26 April 2012

\section{References}

1. Access Economics: The shifting burden of cardiovascular disease: $A$ report prepared for the National Heart Foundation of Australia. In. Canberra, Australia; 2005.

2. Ernst E: Prevalence of use of complementary/alternative medicine: A systematic review. Bull World Health Organ 2000, 78(2):252-257.

3. Australian Institute of Health and Welfare: Australia's Health 2006. In: Cat No AUS 73. Canberra: AlHW; 2006. 
4. The regulation of complementary medicine in Australia: An overview: [www.tga.gov.au/cm/cmreg-aust.ht].

5. : What is CAM?:.; [http://nccam.nih.gov/health/whatiscam/].

6. Lee M, Pittler M, Guo R, Ernst E: Qigong for hypertension: a systematic review of randomized clinical trials. J Hypertens 2007, 25(8):1525-1532.

7. Pepe S, Marasco S, Haas S, Sheeran F, Krum H, Rosenfeldt F: Coenzyme Q10 in cardiovascular disease. Mitochondrion 2007, 7(Supplement 1):S154-S167.

8. Barnes P, Bloom B, Nahin R: Complementary and Alternative Medicine Use Among Adults and Children: United States, 2007. In: CDC National Health Statistics Report \#12. 2008.

9. Wood M, Stewart R, Merry H, Johnstone D, Cox J: Use of complementary and alternative medical therapies in patients with cardiovascular disease. Am Heart J 2003, 145:806-812.

10. Stys T, Stys A, Kelly P, Lawson W: Trends in use of herbal and nutritional supplements in cardiovascular patients. Clin Cardiol 2004, 27(2):87-90.

11. Quan H, Ghali W, Verhoef M, Norris C, Galbraith P, Knudtson M: Use of chelation therapy after coronary angiography. Am J Med 2001, 111(9):686-691.

12. Yeh $G$, Davis R, Phillips R: Use of complementary therapies in patients with cardiovascular disease. Am J Cardiol 2006, 98:673-680.

13. Amira O, Okubadejo N: Frequency of complementary and alternative medicine utilization in hypertensive patients attending an urban tertiary care centre in Nigeria. BMC Compl Alternative Med 2007, 7:(1)30.

14. Gohar F, Greenfield S, Beevers DG, Lip G, Jolly K: Self-care and adherence to medication: a survey in the hypertension outpatient clinic. BMC Comp/ Alternative Med 2008, 8(1):4.

15. Ai A, Bolling S: The use of complementary and alternative therapies among middle-aged and older cardiac patients. Am J Med Qual 2002, 17:21-27.

16. Barraco D, Valencia D, Riba A, Nareddy S, Draus C, Schwartz S: Complementary and alternative medicine (CAM) use patterns and disclosure to physicians in acute coronary syndrome patients. Complement Ther Med 2005, 13:34-40.

17. Blackmer J, Jefromova L: The use of alternative therapies in the Saskatchewan stroke rehabilitation population. BMC Compl Alternative Med 2002, 2(1):7

18. Krasuski RA, Michaelis K, Eckart RE: The cardiovascular patient's perceptions of complementary and alternative medicine. Clin Cardiol 2006, 29(4):161-164.

19. Liu EH, Turner LM, Lin SX, Klaus L, Choi LY, Whitworth J, Ting W, Oz MC: Use of alternative medicine by patients undergoing cardiac surgery. $J$ Thorac Cardiovasc Surg 2000, 120(2):335-341.

20. Shafiq N, Gupta M, Kumari S, Pandhi P: Prevalence and pattern of use of complementary and alternative medicine (CAM) in hypertensive patients of a tertiary care center in India. Int J Clin Pharmacol Therapeut 2003, 41 (7):294-298.

21. Martinez-Selles M, Garcia Robels J, Munoz R, Serrano J, Frades E, Dominguez Munoa M, Almendral J: Pharmacological treatment in patients with heart failure: patients knowledge and occurrence of polypharmacy, alternative medicine and immunizations. Eur J Heart Fail 2004, 6:219-226.

22. Artz MB, Harnack LJ, Duval SJ, Armstrong C, Arnett DK, Luepker RV: Use of Nonprescription Medications for Perceived Cardiovascular Health. Am J Prev Med 2006, 30(1):78-81.

23. Buettner C, Phillips RS, Davis RB, Gardiner P, Mittleman MA: Use of Dietary Supplements Among United States Adults With Coronary Artery Disease and Atherosclerotic Risks. Am J Cardiol 2007, 99(5):661-666.

24. Lee J, Kim J: Factors Affecting the Use of Dietary Supplements by Korean Adults: Data from the Korean National Health and Nutrition Examination Survey III. J Am Diet Assoc 2009, 109(9):1599-1605.

25. Pharand C, Ackman M, Jackevicius C, Paradiso-Hardy F, Pearson G: Canadian Cardiovascular Pharmacists Network: Use of OTC and herbal products in patients with cardiovascular disease. Ann Pharmacother 2003, 36:899-904.

26. Zick S, Blume A, Aaronson K: The prevalence and pattern of complementary and alternative supplement use in individuals with chronic heart failure. J Card Fail 2005, 11:586-589.

27. Wong RS, Cheng G, Chan TY: Use of Herbal Medicines by Patients Receiving Warfarin. Drug Saf 2003, 26(8):585.

28. Yilmaz M, Yontar O, Turgut O, Yilmaz A, Yalta K, Gul M, Tandogan I: Herbals in cardiovascular practice: Are physicians neglecting anything? Int J Cardiol 2007, 122(1):48-51.

29. Ackman M, Campbeel J, Buzak K, Tsuyuki R, Montague T, Teo K: Use of nonprescription medications by patients with congestive heart failure. Ann Pharmacother 1999, 33(6):674-679.
30. Albert N, Rathman L, Ross D, Walker D, Bena J, Mclntyre S, Philip D, Siedlecki S, Lovelace R, Fogarty A, et al: Predictors of Over-the-Counter Drug and Herbal Therapies Use in Elderly Patients with Heart Failure. J Card Fail 2009, 15(7):600-606.

31. Chagan L, Bernstein D, Cheng J, Kirschenbaum H, Rozenfeld V, Caliendo G, Meyer J, Mehl B: Use of biological based therapy in patients with cardiovascular diseases in a university-hospital in New York City. BMC Compl Alternative Med 2005, 5:4.

32. Leung $Y$, Tamim H, Stewart D, Arthur H, Grace S: The prevalence and correlates of mind-body therapy practices in patients with acute coronary syndrome. Complement Ther Med 2007.

33. Decker C, Huddleston J, Kosiborod M, Buchanan DM, Stoner C, Jones A, Banerjee S, Spertus JA: Self-Reported Use of Complementary and Alternative Medicine in Patients With Previous Acute Coronary Syndrome. Am J Cardiol 2007, 99(7):930-933.

34. Greenfield S, Pattison H, Jolly K: Use of complementary and alternative medicine and self-tests by coronary heart disease patients. BMC Compl Alternative Med 2008, 8(1):47.

35. Dal Corso E, Bondiani A, Zanolla L, Vassanelli C: Nurse educational activity on non-prescription therapies in patients with chronic heart failure. Eur J Cardiovasc Nurs 2007, 6(4):314-320.

36. Dickersin K: Systematic reviews in epidemiology: why are we so far behind? Int J Epidemiol 2002, 31:6-12.

37. Sanderson S, Tatt ID, Higgins JP: Tools for assessing quality and susceptibility to bias in observational studies in epidemiology: a systematic review and annotated bibliography. Int J Epidemiol 2007, 36 (3):666-676.

38. Bishop F, Prescott P, Chan Y, Saville J, Von Elm E, Lewith GT: Prevalence of complementary medicine use in pediatric cancer: a systematic review. Pediatrics 2010, 125:768-776.

39. Saha S, Chant D, Mcgrath J: Meta-analyses of the incidence and prevalence of schizophrenia: conceptual and methodological issues. Int J Meth Psychiatr Res 2008, 17(1):55-61.

40. Bell RA, Suerken CK, Grzywacz JG, Lang W, Quandt SA, Arcury TA: CAM Use Among Older Adults Age 65 or Older with Hypertension in the United States: General Use and Disease Treatment. J Alternative Compl Med 2006, 12(9):903-909.

41. Shah SH, Engelhardt R, Ovbiagele B: Patterns of complementary and alternative medicine use among United States stroke survivors. J Neurol Sci 2008, 271(1-2):180-185.

42. Archer SL, Stamler J, Moag-Stahlberg A, Van Horn L, Garside D, Chan Q, Buffington JJ, Dyer AR: Association of Dietary Supplement Use with Specific Micronutrient Intakes among Middle-Aged American Men and Women: The INTERMAP Study. J Am Diet Assoc 2005, 105(7):1106-1114.

43. Harris $P$, Rees $R$ : The prevalence of complementary and alternative medicine use among the general population: a systematic review of the literature. Compl Ther Med 2000, 8:88-96.

44. William HF, Poojitha B, Christine C: Alternative and Complementary Medicine for Preventing and Treating Cardiovascular Disease. Disease Month DM 2009, 55(3):121-192.

45. Vora C, Mansoor G: Herbs and alternative therapies: Relevance to hypertension and cardiovascular diseases. Curr Hypertens Rep 2005, 7 (4):275-280

doi:10.1186/1471-2458-12-299

Cite this article as: Grant et al:: The use of complementary and alternative medicine by people with cardiovascular disease: a systematic review. BMC Public Health 2012 12:299. 